\title{
Exploring PC-Telephone Convergence with the Enhanced Telephony Prototype
}

\author{
JJ Cadiz, Attila Narin, Gavin Jancke, Anoop Gupta \\ Microsoft Real-Time Collaboration \\ One Microsoft Way, Redmond, WA 98052 \\ jjcadiz@microsoft.com
}

\author{
Michael Boyle \\ Dept. of Computer Science \\ University of Calgary \\ Calgary, Alberta Canada T2B 1X5
}

\begin{abstract}
Industry trends suggest that the PC and telephone user experiences will converge over the next several years. This convergence raises important questions for the HCI community: how should the PC-phone user experience be designed, and how does PC-phone technology affect work practices? This paper focuses on the first question and provides some initial data on the second question. We describe a PC-phone prototype we built called Enhanced Telephony, and we report data from an eight month field deployment of Enhanced Telephony within our company where over 7,000 people installed the prototype. Results indicate that PC-phone software is a promising technology for the workplace and that the most valuable features may be those that help people manage their incoming calls.
\end{abstract}

Categories \& Subject Descriptors: H.5.2 User Interfaces-Graphical user interfaces, prototyping, evaluation/methodology. H.5.3 Group and Organization interfaces-Synchronous interaction.

General Terms: Design

Keywords: Computer Telephony Integration (CTI), telephones, computer mediated communication

\section{INTRODUCTION}

With the advent of e-mail, instant messaging, and the World Wide Web, the PC has become an increasingly important communication tool. However, one of the most pervasive communication technologies, the telephone, has remained largely divorced from the PC for the typical user.

Industry trends suggest this will soon change. VoIP (voice over internet protocol) technology, which allows calls to travel from PC to PC over the internet, is gathering momentum as an inexpensive alternative to traditional telephony systems. Market analysts predict that by 2006, VoIP system sales will outpace traditional telephony systems [8]. This year, Dartmouth University started

Permission to make digital or hard copies of all or part of this work for personal or classroom use is granted without fee provided that copies are not made or distributed for profit or commercial advantage and that copies bear this notice and the full citation on the first page. To copy otherwise, or republish, to post on servers or to redistribute to lists, requires prior specific permission and/or a fee.

CHI 2004, April 24-29, 2004, Vienna, Austria.

Copyright 2004 ACM 1-58113-702-8/04/0004...\$5.00. offering students the choice to use VoIP "softphones" on their PCs in lieu of standard phones [6], and Skype, a VoIP application from the founders of the $\mathrm{P} 2 \mathrm{P}$ file sharing application KaZaA, was downloaded over half a million times in its first two weeks of availability [13].

The coming convergence of PCs and telephones raises two important questions for the HCI community. First, how should the PC-phone user experience be designed? Today, many PC-phone UIs are pictures of phones placed on the PC screen, such as in Figure 1. While this type of interface may be a familiar one for users, there are dangers in using designs in the virtual world that were meant for the physical world. For example, some PC-phone interfaces require the user to dial the phone by clicking a virtual handset to pick it up and then clicking ten buttons to dial a ten-digit number - a tedious set of steps. Furthermore, some features (such as call transfer and multiparty conference calling) are difficult to use on standard phones. By placing the telephone user experience on the PC, UI designers have the opportunity to make advanced telephone features easier to use.

In addition to simplifying current functionality, PC-phone software can also introduce a variety of new features by taking advantage of the added processing power and access to information that PCs have. For example, PCs contain quite a bit of information about the status of their users (schedules, locations, whom they are meeting with, etc.) that could be used to automatically handle incoming calls.

The second major question for the HCI community is how PC-phone technology affects the way people work. It makes existing advanced phone features easier to use, and it can introduce a variety of new features (like transferring all calls to voicemail if I am in a meeting in my office). How do these technologies change the way people work?

This paper describes our team's exploration of these questions via the deployment within our company of a prototype called Enhanced Telephony. The focus of this paper is the design of PC-phone systems, and some early data are presented on how these types of systems affect work practices. The following sections will discuss prior work in the area of PC-phone convergence, the Enhanced Telephony prototype, the field study of the prototype, and lessons learned. 


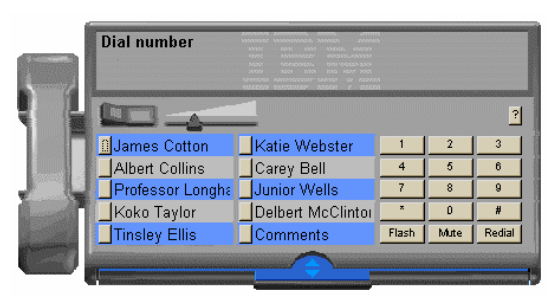

(a) IBM RealPhone

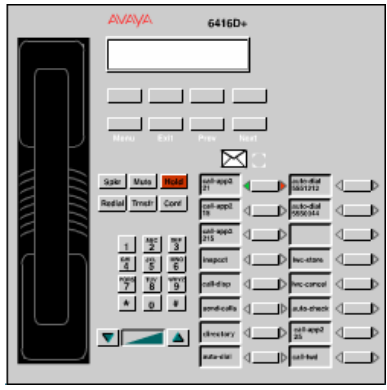

(b) Avaya IP Softphone

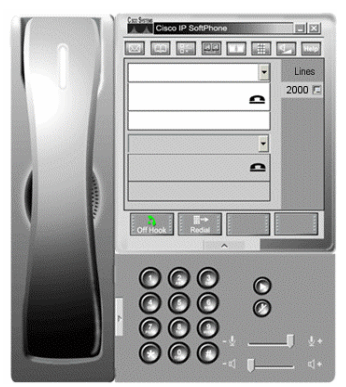

(c) Cisco IP Softphone

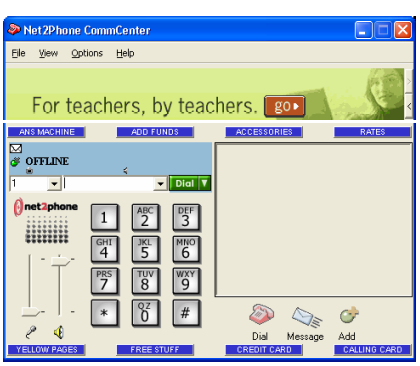

(d) Net2Phone

Figure 1: Examples of PC-phone user interfaces. The IBM RealPhone is from 1996 and the others are from 2003.

\section{PRIOR WORK IN PC-PHONE CONVERGENCE}

While basic telephone tasks such as answering a call or dialing a number remain straightforward, researchers have found that the more advanced telephone features (conference calling, call waiting, call camp, etc.) are considerably more difficult to use. As a result, people tend not to use these features, even though they would likely benefit from them $[5,9,18]$.

As [7] points out, researchers have taken two approaches to address this issue: stay within the bounds of the typical phone design, or extend the typical phone's design. [3], [7], and [17] are good examples of the first approach. This line of research usually examines the design of audio menus ("press 1 if you are calling about a current account, press 2 if...") and how to best design input methods when the system is limited to a small keypad and voice.

The second approach-extending the phone's current design - is the focus of this paper. Researchers have explored the augmentation of telephones with mice, keyboards, and screens as a way to address usability issues [19]. In user tests, both [9] and [18] found that telephones augmented with screens improved usability and were more liked by users when compared to standard phones or phones enhanced with audio menus.

Furthermore, combined PC-phone systems have been widely used for years in call centers where the telephone is used for product support, directory assistance, telemarketing, etc. In these cases, jobs primarily consist of talking on the phone, and even a few seconds of added productivity per employee can lead to significant financial savings for companies. PC-phone interfaces for call centers tend to be designed for highly specialized tasks, and prior research in this area has focused on low-level analysis to determine how the UI can be redesigned to be as efficient as possible for expert users [12].

Based on studies like those from [9] and [18], the combination of the PC and telephone for the everyday employee seems promising. However, the design task is a difficult one. The IBM RealPhone from 1996 (Figure 1a) is an example of a "softphone" (a "software phone" where one uses the $\mathrm{PC}$ as a phone). Its design was criticized by the usability community for a variety of reasons, including inappropriately using metaphors from the physical world in the design of a virtual interface [11]. Despite this critique and some excellent examples of iterative PC-phone design in the HCI community (e.g., [19]), many of today's PCphone interfaces still look and act like physical phones. Figures 1b, 1c, and 1d show software phones commercially available today from three of the leading companies in the VoIP industry: Avaya [2], Cisco [4], and Net2Phone [16].

Many commercial software phones also neglect the power and access to information that today's PCs have. This power and information can be used to address common problems with telephones today. For example, both Awarenex [20] and the Live Addressbook [14] were systems where users could see others' phone status and location with an interface similar to today's instant messaging buddy lists. People could use this information to make smarter decisions about contacting people, and Awarenex allowed people to place calls using their handheld computers and a nearby phone.

Another good example of using the power of the PC to create rich phone scenarios is Quiet Calls [15], a system that allowed people to answer their cell phones in contexts where it would normally be inappropriate (for example, in meetings or movie theaters) and "talk" by selecting preconfigured messages from the phone's keypad. Apple's iSync software [1] uses the power of the PC to keep contact information synchronized between a cell phone and a PC.

We extend this existing research in two ways: we present a PC-phone prototype that was designed with several integrated features to take advantage of the power of the $\mathrm{PC}$, and we report data from a long-term, large-scale field trial of the prototype.

\section{THE ENHANCED TELEPHONY (ET) PROTOTYPE}

To explore the design of PC-phone software for the typical office worker, we built the Enhanced Telephony (ET) prototype. This section describes the user experience and implementation of the prototype.

\section{User Experience}

The main ET UI is shown in Figure 2. ET provides features in three main areas: outgoing calls, incoming calls, and during calls. 
Access to features to forward $\mathrm{my}$ Accesses a history of all $\mathrm{my}$ incoming calls based on my status [10]. outgoing and incoming calls.

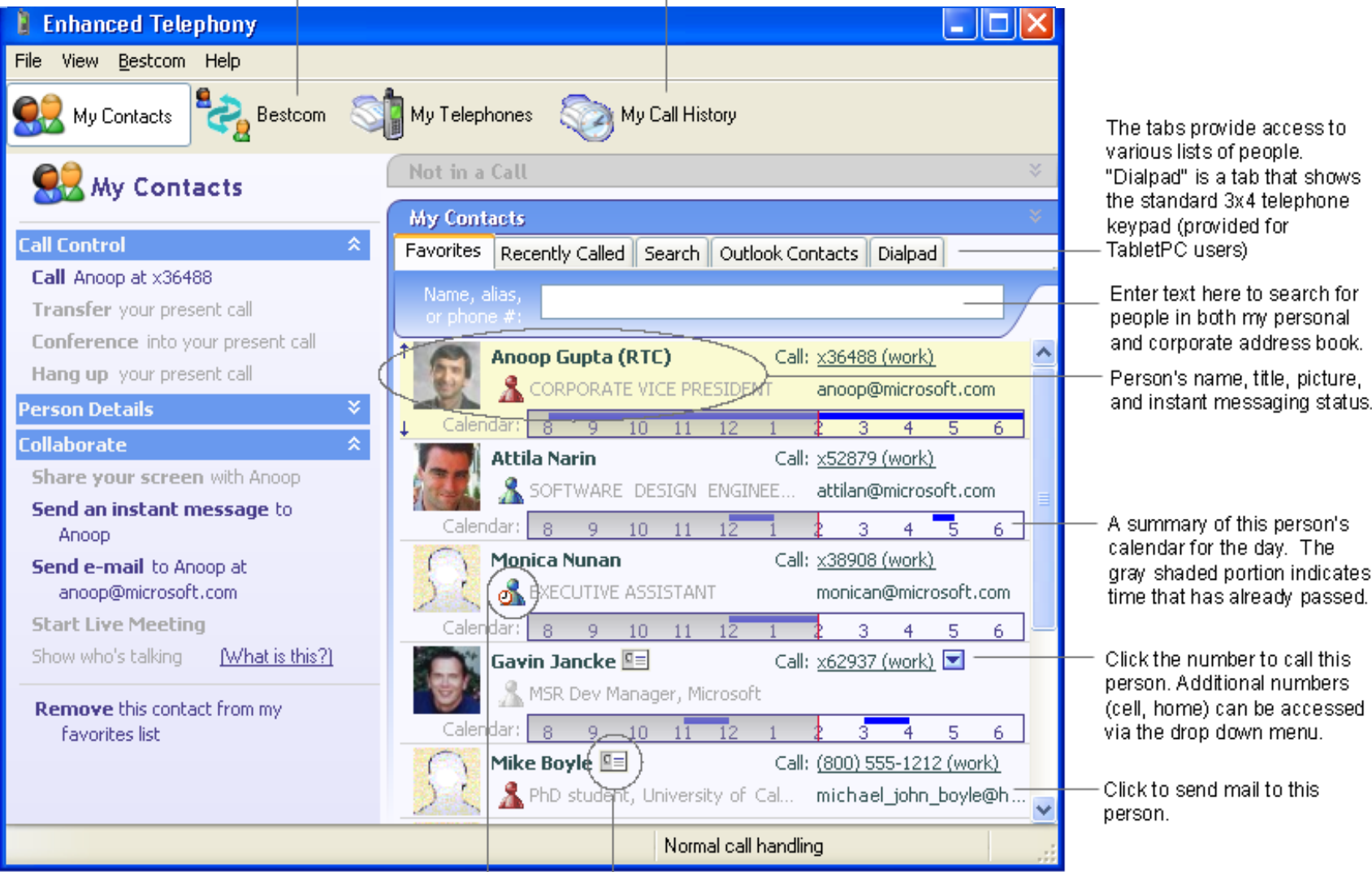

This person is "away" according to Windows instant messenger. This entry is from my personal address book By looking at her calendar, we can guess that she probably Entries without this icon are from the corporate hasn't gotten back from her $12 \mathrm{pm}-2 \mathrm{pm}$ meeting yet. address book.

Figure 2: The Main ET UI when a person is not in a call. When in a call, the list of people is replaced with a list of people on the call, a "hang up" button, and an area for taking notes. In addition, the disabled menu items in the left pane (ex: "share your screen with...") become enabled for use during the call.

\section{Outgoing Calls}

The first step in calling someone is to find their entry in ET. As shown in Figure 1, ET provides several lists of people to browse: a favorites list (similar to a "speed dial" list) initially populated with my co-workers, as determined from the corporate address book; a list of people recently called; and a list of everyone in my personal address book (Microsoft Outlook, in this case). Users can also search for people by entering their first name, last name, or phone number. Search results from both the corporate address book and the user's personal address book are combined.

To call someone, users click the phone number they wish to dial. After clicking a phone number, ET turns on the phone's speakerphone and dials the number. Users do not need to touch their phone in order to place calls, though they may want to pick up the handset if they prefer not to use the speakerphone.

Users may also place calls from within other applications. Microsoft Office applications provide a "smart tag" feature that displays every name in an Office application (Word, PowerPoint, Outlook, etc.) with a drop-down menu that can be extended programmatically. ET extends this menu with commands to call a person. For example, Figure 3 shows that when I am viewing an e-mail, I can call the sender via the smart tag menu.

ET also provides features to make it easier to contact someone. First, an overview of a person's calendar for the day is shown, if available. Second, the person's instant messaging status is shown if the person is using Microsoft Windows Messenger. Examples of instant messenger status include online, busy, on the phone, and idle.

By having easy access to a person's instant messaging status and calendar, people may have better luck when trying to call someone. For example, in Figure 2, if the user tries to call the third person in the list but does not reach her, the user may deduce that she has yet to return from her $12 \mathrm{pm}-2 \mathrm{pm}$ meeting. The user may check back in a few minutes or wait for her presence to change to "online" to try to call her again.

\section{Incoming Calls}

When a user receives a call, a small window (Figure 4) appears in the lower-right corner of the screen. If the call is 


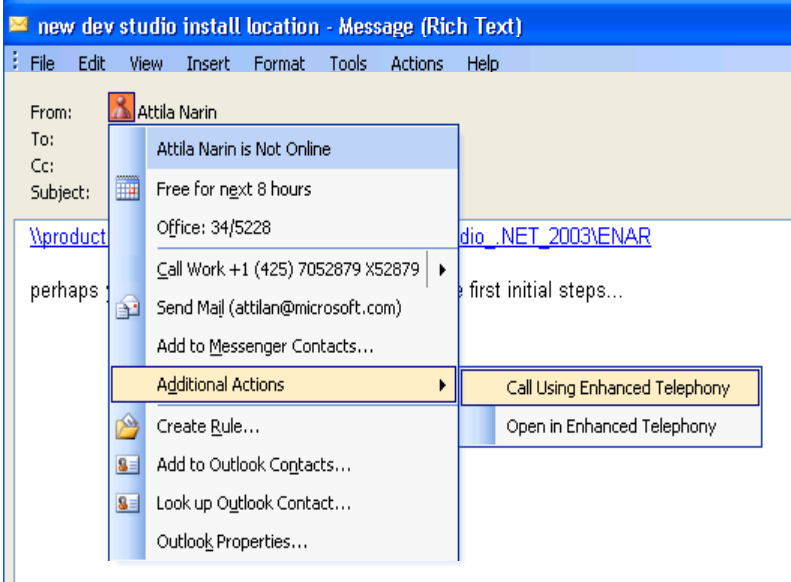

Figure 3: The smart tags in Office 2003 were extended so that people could place calls from places like e-mail messages.

from a person recognized in either the corporate or personal address book, additional information is shown (name, picture, etc.). If the phone number is not recognized, detail about the area code (e.g., "Call from Ohio") is provided.

Users can take one of three actions when a call comes in: they can ignore it, press "Answer" to turn on the phone's speakerphone and answer the call, or select a number and press "Transfer to" to transfer the call. As the next section describes, no physical connection exists between the PC running ET and the telephone; thus, it is possible for someone to see that they are getting a call even though they are not at their desk. With the "Transfer to" button, they can transfer the call to a phone near them (for example, their home phone or cell phone).

Users can also specify actions that ET should take when calls come in. ET can send an e-mail notification any time a call is missed, and ET can also transfer calls automatically based on certain conditions. For example, users can configure ET to transfer all calls to their cell phones whenever their computer is locked, which is typically an indication that they are not at their desks. More advanced call handling policies and infrastructure have also been implemented in ET by the Bestcom project at Microsoft Research. Bestcom allows users to create policies based on a variety of conditions, including inferences about a user's interruptability. The Bestcom work is not covered in this paper, but more detail is available in [10].

\section{During Calls}

When talking on the phone, users can take several actions to enhance the call. They can share screens (using Microsoft NetMeeting), send an instant message, or send email to the person to whom they are talking. ET also makes it easy to transfer the call to another person. Users can also take notes while on the phone. Users can review these notes in the call history where all prior calls are listed.

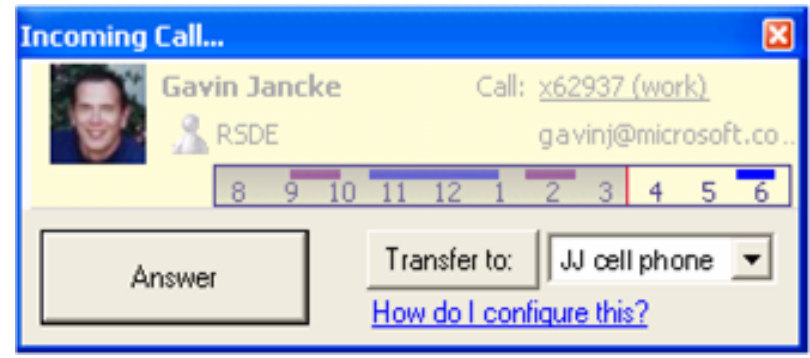

Figure 4: The window displayed when a person receives a call. If possible, ET matches incoming calls to the correct entry in the person's corporate or personal address book.

Users can also configure ET to take a few actions whenever they are on the phone. For example, ET can set a person's instant messenger status to "on the phone" and mute the PC's audio when a call is in progress. (Both the status and audio volume are set back to normal when the phone call ends.) In lieu of muting the PC's audio, ET can pause the person's music player (for example, Microsoft Windows Media Player) and unpause it when the call is finished.

\section{Implementation}

Figure 5 shows a high-level overview of how ET is implemented. All employees at our company's headquarters campus are provided with telephone service via four private branch exchanges (PBXs) from the company Intecom. Intecom provides a set of PBX application programming interfaces called the Open Application Interface (OAI) toolkit. The OAI toolkit provides software functions to control telephones and receive notifications about events that occur for telephones.

When the user places a call with ET, ET sends a request to the server to place the call. The server then translates this request into the appropriate OAI function calls for the PBX. The PBX then sends the appropriate commands to the phone to execute the request. When someone calls an ET user, the reverse happens: the PBX notifies the server via $\mathrm{OAI}$, and the server notifies the correct ET client.

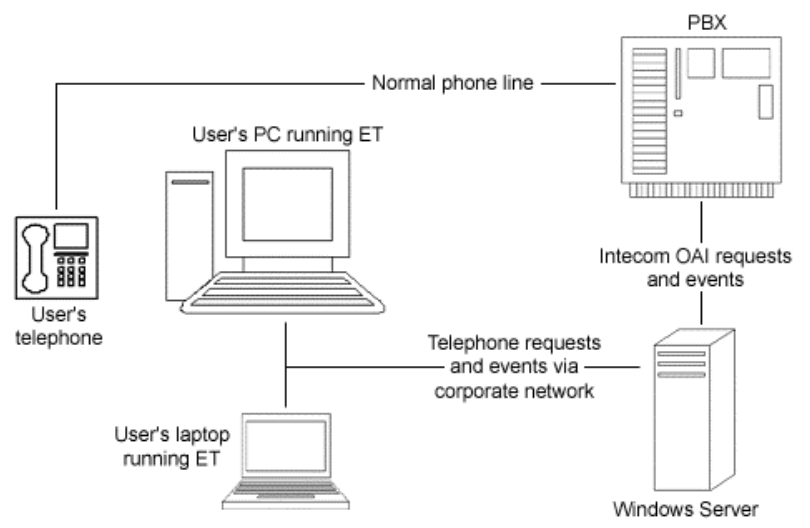

Figure 5: An overview of the implementation architecture for ET. The field deployment consisted of four PBXs and four servers. 

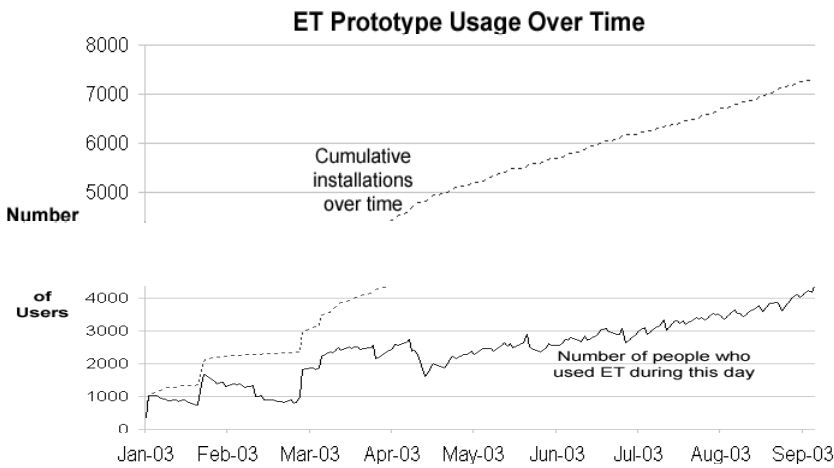

Figure 6: ET usage over time. The non-linear adoption rate prior to March was due to server limitations put in place to protect the system until it could support large numbers of users.

A few important notes need to be highlighted with regard to this implementation. First, the ET system has no access to the audio from the call. ET is only able to control phones; it cannot listen to or participate in conversations. Second, note in Figure 5 that there is no direct connection between users' PCs and their telephones. As a result, a person can run ET on any computer in the world with a connection to the corporate network: office computers, laptops with wireless connections, home computers, etc. Third, ET did not interfere with normal phone usage. People could always use their phones as they did before installing ET.

\section{FIELD STUDY}

To gather data to help answer our major research questions, we conducted a field deployment of ET. On January 9, 2003, ET was made available for general use on our company's main campus. No advertising was done with the exception that 120 volunteers who had helped us test initial versions of ET were told that others on the campus could install ET if they wanted to. Aside from these initial 120 users, people could only find out about ET if someone else told them about it.

Figure 6 shows the usage of ET over the next eight months. By the end of the time period studied for this paper, over 7,300 employees (more than 1 in 4 people on our company's main campus) had installed ET, and ET was being used by over 4,300 people every day.

\section{Data Collection Methodology}

Two methods were used to collect data about ET usage. ET was instrumented such that all major events (placing a call, receiving an incoming call, transferring a call, etc.) were logged to a database while ET was running. Usage data reported in this paper covers the eight month period from January 9 through September 9, 2003.

In addition, three separate surveys were conducted of the ET user population. First, before installing ET, all users were asked to fill out a brief survey about themselves and their phone use. 4,407 out of 7,342 people who installed ET filled out this survey (a $60 \%$ response rate).

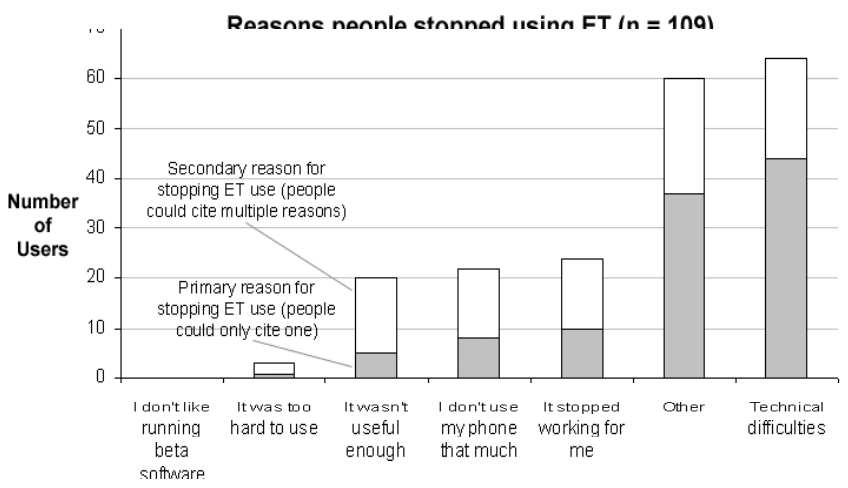

Figure 7: Reasons people stopped using ET. Most of the "other" reasons had to do with annoyances (ex: slowing down a PC's boot time), incompatibilities with other beta software, or forgetting to reinstall ET when getting a new computer.

Second, in September 2003, 480 people who used ET for a while and then stopped were surveyed to determine why they were no longer using ET. 134 users responded, of which 25 responses were removed because people said they were still using ET but had not used it lately (for example, because of being on vacation or a business trip).

Third, a random sample of 750 people who were still using ET in September 2003 and who had filled out the preinstallation survey were asked to complete a second, more detailed questionnaire. 246 people responded.

\section{Results \& Discussion}

The general reaction to ET was overwhelmingly positive. $46 \%$ of current ET users said ET performed above their expectations $(49 \%$ said it performed as expected). Furthermore, $94 \%$ of current ET users stated that they had recommended ET to their colleagues.

Figure 6 does show that about one-third of people stopped using ET after a while. However, as Figure 7 shows, the most often cited reason for stopping ET use was technical difficulties (memory leaks, causing other applications to fail, etc.) typical of a prototype.

Aside from the general feelings about ET usage, an analysis of the data collected throughout the field study yields several interesting findings. For instance, even though email and instant messaging are both used at our company, the phone remains an important tool for communication. Prior to installing ET, the median response to the statement "The phone is critical to my day-to-day work" was 4 ("agree") on a 5-point scale. People reported that they used the phone, on average, two to five times each day.

Data from the pre-install survey also indicate that trying to contact someone via phone is often difficult. The median response to the question "When I try to call someone, I reach them right away (no "phone tag' necessary)" was 2 (disagree). Further data confirm previous research stating that advanced phone features (including features meant to reduce "phone tag," like call forwarding) are not commonly used. Of the six advanced features we asked about, two 
had a median response of being used "less than once a month," and four had a median response of being "never" used.

As noted in the introduction, one major question for the HCI community is how PC-phone convergence can help to address these issues. The following sections discuss ET's successes and failures in this area.

\section{Improving the Dialing Experience}

ET included several features to improve the experience of finding and dialing someone. The data indicate that these features were largely successful, although the features were more useful for users who called a broader set of people.

Table 1 shows that one of the top features was the ability to search for someone and click the phone number to dial it. Being able to search across both corporate and personal address books at the same time was also considered very useful. However, the $\log$ data indicate that most calls $(73 \%)$ were made by picking up the phone and dialing instead of using ET.

To explore this inconsistency, we created a measure of call breadth to determine whether people were dialing the same phone number repeatedly or dialing a variety of phone numbers. The measure ranged from 1 (people for whom half of all calls went to only one phone number) to 24 , with a median of 3 . Thus, most people typically called a relatively small amount of phone numbers.

The breadth of phone numbers called helps to explain why ET was not used to dial more often: people who called a narrower set of phone numbers used ET to dial a significantly smaller percentage of their calls $\left(\mathrm{r}_{\mathrm{s}}=0.51, \mathrm{p}<\right.$ $.001, \mathrm{n}=236)$ and also rated the feature of searching for someone in ET and dialing significantly lower $\left(\mathrm{r}_{\mathrm{s}}=0.34, \mathrm{p}\right.$ $<.001, \mathrm{n}=180$ ). Phone number memorization is the most likely explanation: if a person dials a small set of numbers frequently, that small set of numbers may become memorized over time. In the survey of current ET users, 153 people who stated that they do not dial all their calls with ET were asked to indicate why this was the case. The top reason was that the number being dialed was memorized (selected by 118 , or $77 \%$, of respondents).

One other statistic with regard to dialing with ET is worth noting: people could use ET to dial phone numbers via a virtual keypad similar to the keypads that are prominently shown in the UIs in Figure 1. As Table 1 shows, this was the lowest rated feature in the entire user experience (although it is unclear how this rating would change if the physical phone keypad were not available as an alternative).

\section{Improving the In-Call Experience}

While the features designed to improve the dialing experience were rated well, the features designed to support people while in calls were not as successful. As Table 1 shows, sharing screens and taking notes while in a call
Table 1: Ratings of ET features from current users of ET. Only people who were familiar with a feature were asked to rate it, thus the differing number of respondents in the $\mathrm{N}$ column. Features were rated on the following scale: 1 = not useful, 2 = somewhat useful, $3=$ very useful, 4 = can't live without

\begin{tabular}{|c|c|c|c|c|}
\hline Feature & $\mathbf{N}$ & $\begin{array}{c}\text { Av } \\
\text { g }\end{array}$ & $\begin{array}{l}\text { Std } \\
\text { de } \\
v\end{array}$ & $\begin{array}{l}\text { Med- } \\
\text { ian }\end{array}$ \\
\hline $\begin{array}{l}\text { Receiving an e-mail when you miss a } \\
\text { call }\end{array}$ & 238 & 3.3 & 0.7 & 3 \\
\hline $\begin{array}{l}\text { Automatic call forwarding based on } \\
\text { your status }\end{array}$ & 137 & 3.1 & 0.7 & 3 \\
\hline Incoming call notification window & 235 & 3.1 & 0.7 & 3 \\
\hline $\begin{array}{l}\text { Manually transferring a call to another } \\
\text { phone (like your cell phone) while } \\
\text { your phone is ringing (a.k.a. "Quick } \\
\text { Transfer"). (Typically used on a PC } \\
\text { away from the desk phone, like a } \\
\text { laptop or home PC). }\end{array}$ & 100 & 3.1 & 0.9 & 3 \\
\hline $\begin{array}{l}\text { Muting computer's audio while on the } \\
\text { phone }\end{array}$ & 148 & 3.1 & 0.8 & 3 \\
\hline $\begin{array}{l}\text { Calling by searching for someone in } \\
\text { ET and clicking their phone number }\end{array}$ & 183 & 3.0 & 0.7 & 3 \\
\hline $\begin{array}{l}\text { Call forwarding based on who's } \\
\text { calling (see [10] for more results } \\
\text { regarding ET's advanced call } \\
\text { forwarding features] }\end{array}$ & 93 & 3.0 & 0.8 & 3 \\
\hline $\begin{array}{l}\text { Setting instant messenger status to } \\
\text { "on the phone" while on the phone }\end{array}$ & 152 & 2.9 & 0.8 & 3 \\
\hline $\begin{array}{l}\text { Being able to search across the } \\
\text { corporate address book and your } \\
\text { Outlook contacts at the same time }\end{array}$ & 164 & 2.9 & 0.7 & 3 \\
\hline Calling from Outlook Smart Tags & 86 & 2.8 & 0.7 & 3 \\
\hline Calling from ET's Recently Called tab & 198 & 2.7 & 0.7 & 3 \\
\hline Seeing people's free/busy calendars & 145 & 2.7 & 0.8 & 3 \\
\hline Calling from ET's Favorites tab & 205 & 2.7 & 0.8 & 3 \\
\hline Call history & 185 & 2.7 & 0.8 & 3 \\
\hline Initiating conference calls using ET & 36 & 2.6 & 0.8 & 3 \\
\hline $\begin{array}{l}\text { Transferring the call while on the } \\
\text { phone }\end{array}$ & 70 & 2.5 & 0.8 & 3 \\
\hline Taking notes while on the phone & 93 & 2.3 & 0.8 & 2 \\
\hline Seeing people's pictures & 156 & 2.1 & 0.8 & 2 \\
\hline $\begin{array}{l}\text { Having ET play a sound when } \\
\text { someone calls vou (rina tones) }\end{array}$ & 93 & 2.1 & 0.9 & 2 \\
\hline
\end{tabular}

were two of the lowest rated features. These low ratings may be due to poor implementation, a lack of need for these features, or both.

However, the features involving ET taking some simple actions when people use their phones were rated higher. Muting the PC's audio and setting the person's instant messenger status to "on the phone" when the phone was in use were both rated as very useful. The "pause my music player when I am using the phone" feature was one of the most requested features from the user community.

Helping Users with Incoming Calls

Of all ET's features, those that helped people manage their incoming calls were rated the most useful. In fact, the top four features in Table 1 all deal with incoming calls. Users often e-mailed us to tell us of the value of these features: 
"I've been using ET for a while now, and it's outstanding. It has already saved me on a couple of big issues, simply by making me more available."

- An operations manager

"In one case a manager in my group called me. I sent her an e-mail immediately saying 'I see you called I'm not at my desk but I'm on e-mail, let me know what you need.' We solved her issue immediately."

- A content development manager

$46 \%$ of ET users stated that the main reason they continued to use ET was because it helped them work with people who were trying to call them $(36 \%$ stated the improved dialing experience was the reason, and $19 \%$ chose other reasons).

The median response to the statement that ET helps other people reach them faster was 4 ("agree"). 178 people who agreed or strongly agreed to the question were asked to indicate all the reasons why. 54 said that it was because they used ET away from their desk and manually transferred calls to their location, 79 said it was because they configured ET to automatically transfer calls to their location, and 148 people said it was because they called people back when they received ET's e-mail notification that they had missed a call. In fact, Table 1 shows that the missed call e-mail was ET's top rated feature. Users often commented in surveys on how much they enjoyed the missed call e-mail feature:

"Knowing what [calls I've missed] allows me to get back to people, sometimes after they've given up, so they're pleasantly surprised."

- A test lead

"I get a number of calls and people do not always leave me messages so being able to get a mail allows me to either move that dialogue to email or I can call them right back."

\section{- A business development manager}

Table 1 also shows that automatic and manual call forwarding were very popular features. Users wrote in surveys:

"The basic call [forwarding] is the absolute best feature of the product."

- A program manager

"Now that I have the dynamic [call forwarding feature], people can always get a hold of me, which also simplifies the path that people have to take to escalate issues to me off hours."

- A senior systems engineer

It is interesting to note that prior to installing ET, people were asked how often they set their phone to automatically forward calls to them. (People could do this manually by picking up the handset, dialing $* 3$, and then dialing the forwarding number. Dialing \# 3 would turn off forwarding.) The average response was "less than once a month" and the median response was "never." However, configuring ET to transfer calls based on one's status (e.g., forward calls when my instant messenger status is "away") was the second most popular feature. This point lends support to prior researchers' assertions that people would likely benefit from advanced features on their phone if they were easier to use $[5,9,18]$.

How does PC-phone technology affect how people work? Another important question for the HCI community is how PC-phone technology affects the way people work. This section begins to examine a few questions in this area.

First, if ET makes it easier to call people, do people place more calls in lieu of other forms of communication? The data indicate that people do not place more calls when using ET. People were asked before and after using ET how often they used their phones, and a Wilcoxon test found no significant change over time $(\mathrm{z}=\mathrm{-}$ $0.77, \mathrm{p}=0.44)$. Furthermore, when people were asked to respond to the statement "I call other people more often now that I have ET" the median response was 3 ("neither agree nor disagree"). We asked the 71 people who "agreed" or "strongly agreed" to this question how they communicated with others prior to using ET. Most people (56) said that they sent e-mail, 32 said that they went to people's offices more, and 18 said they used instant messenger.

Second, does ET help eliminate situations where two people who want to talk on the phone have trouble reaching each other (also referred to as "phone tag")? As noted earlier, the median response to the question "When I try to call someone, I reach them right away (no 'phone tag' necessary)" was 2 ("disagree"). However, the data on whether ET helps to eliminate phone tag are mixed.

When current ET users were asked if they felt that they played less phone tag as a result of using ET, the median response was 3 ("neither agree nor disagree"). However, feelings of phone tag were measured before and after ET usage and were found to worsen slightly over time (mean response before ET usage: 2.62; after ET usage: 2.49). A Wilcoxon test found this change to be significant at the 0.1 level, but not the .05 level $(\mathrm{z}=-1.90, \mathrm{p}=0.06)$. It is unclear whether this change over time was due to ET usage or some other external factor (for example, the post-test question was asked at the end of summer when several people at our company take vacations).

Interestingly, people who had more calls automatically transferred to them (according to log data) tended to feel more strongly that ET helped reduce feelings of phone tag $\left(\mathrm{r}_{\mathrm{s}}=.19, \mathrm{p}=0.002, \mathrm{~N}=245\right)$. Phone tag occurs when you try to call someone and they are not at their phone, or when they try to call you and you are not at your phone. The data indicate that latter situation my happen less when people use ET's call forwarding features. One user wrote of how ET helps in this situation: 
"When I have been in training, and had my laptop with me, I am able to take critical calls (and I know if they are critical or not usually based on the caller ID) right away by quick transferring them to my cell phone."

- A tools engineer

However, more study is needed to determine the effect of ET when it comes to helping people reach each other faster.

\section{CONCLUSION AND FUTURE WORK}

This work highlights two interesting findings: first, that the most valuable PC-phone features do not seem to be related to making it easier to call people, but rather to making it easier to be aware of and deal with incoming calls; and second, that it is possible to build a great PC-phone user experience without making the UI look like a phone.

However, several areas remain for exploration. First, this paper has only started to explore a few simple questions on how PC-phone technology affects work practices. Future work could focus on whether and how PC-phone technology helps people work more effectively.

Second, we did not examine any features that required access to the audio from the call. For example, ET could not act as a personal answering machine, and people could not talk on the phone through their PC microphone and speakers. Quiet Calls [15] is a great example of the types of innovative features that could be tested once one has access to the audio stream for a call.

Third, better tools need to be designed to support people while they are talking on the phone. ET seems to have done a good job of improving the outgoing and incoming call experiences, but with a few exceptions, the features we designed for supporting people while in a call were not viewed as useful.

Fourth, ET only allowed people to interact with their desk phones at work. However, many people have more than one phone, and for many people, a mobile phone is their primary phone. What should the user experience be for PC-phone software that links with mobile phones, or software that allows people to link to their home, work, and mobile phones? What innovative features are possible?

Despite these issues, ET continues to be used by several thousand employees in our company, and every day companies like Cisco are working to move the world from traditional phone systems to VoIP technology. The HCI community has a significant opportunity to help shape the user experience of the future of voice communication technology.

\section{REFERENCES}

[1] Apple iSync. http://www.apple.com/isync

[2] Avaya IP Softphone. http://www.avaya.com
[3] Brewster, S. Navigating Telephone-Based Interfaces with Earcons. HCI'97 Conference on People and Computers XII, 39-56.

[4] Cisco IP Softphone. http://www.cisco.com/ en/US/products/sw/voicesw/ps1860/

[5] Griffeth, N. Making a Simple Interface Complex: Interactions among Telephone Features. CHI 1996 Conference Companion, 244-245.

[6] Hafner, K. Revolution in the Dorms of Dartmouth. The New York Times, September 23, 2003, p. C7.

[7] Halstead-Nussloch, R. The Design of Phone-Based Interfaces for Consumers. Proc. CHI 1989, 347-352.

[8] Herrell, H. Market Overview 2003: IP Telephony Voice Communications Systems. Giga Information Group, June 2, 2003.

[9] Herring, R., List, J., and Youngs, E. Screen-Assisted Telephony and Voice Service Usability. Proceedings Human Factors Society 36th Annual Meeting, 1992, 221.

[10] Horvitz, E., Apacible, J., Subramani, M., Sarin, R., Koch, P., Cadiz, J., Narin, A., and Rui, Y. Experiences with the Design, Fielding, and Evaluation of a RealTime Communications Agent. Microsoft Research Technical Report MSR-TR-2003-98.

[11] Isys Information Architects. Interface Hall of Shame: IBM's Real Phone. http://digilander.libero.it/ chiediloapippo/Engineering/iarchitect/

[12] John, B. Extensions of GOMS Analyses to Expert Performance Requiring Perception of Dynamic Visual and Auditory Information. Proc. CHI 1990, 107-116.

[13] Latour, A., and Delaney, K. J. KaZaA Creators Connect to Phones. The Wall Street Journal, September 19, 2003, p. B5.

[14] Milewski, A. and Smith, T. Providing Presence Cues to Telephone Users. Proceedings of ACM Conference on Computer-Supported Cooperative Work, ACM Press (2000), 89-96.

[15] Nelson, L., Bly, S., and Sokoler, T. Quiet Calls: Talking Silently on Mobile Phones. Proc. CHI 2001, 74-181.

[16] Net2Phone, http://www.net2phone.com

[17] Resnick, P., and Virzi, R. Skip and Scan: Cleaning Up Telephone Interfaces. Proc. CHI 1992, 419-426.

[18] Roberts, T., and Engelbeck, G. The Effects of Device Technology on the Usability of Advanced Telephone Functions Using Auditory Output. Proc. CHI 1989, 331-337.

[19] Savage, P. Designing a GUI for Business Telephone Users Features. Interactions. 1995, 2(1) 32-41.

[20] Tang, J. C., Yankelovich, N., Begole, J., Van Kleek, M., Li, F., and Bhalodia, J. ConNexus to Awarenex: Extending Awareness to Mobile Users on the Road. Proc. CHI 2001, 221-228. 